\title{
Article
}

\section{Seasonal Monsoon Variations in Surface Currents in the Gulf of Thailand Revealed by High Frequency Radar}

\author{
Suriyan Saramul \\ Department of Marine Science, Faculty of Science, Chulalongkorn University, Bangkok 10330, \\ Thailand \\ E-mail: Suriyan.S@Chula.ac.th
}

\begin{abstract}
Surface currents in coastal waters can be mapped with high frequency radar (HF radar). In this study, month-long surface vector current data from the Upper Gulf, Central Gulf and Lower Gulf of Thailand (UGOT, CGOT, and LGOT, respectively) were analyzed and compared during a northeast (24 January - 22 February 2015) and southwest (25 May - 23 June 2015) monsoon to investigate seasonal patterns. Temporal averaging of surface currents at UGOT indicated no circulation pattern differences between seasons. Area averaging revealed that flow was strongly tidally influenced; however, a tidal influence was observed during the southwest monsoon at CGOT and LGOT. During the northeast and southwest monsoons at both CGOT and LGOT, residual current flowed in the northwest and northeast directions, respectively. Tidal ellipse analysis of diurnal (K1 and O1) and semi-diurnal (M2 and S2) tidal components demonstrated that the magnitude and rotation of each component differed from site to site and season to season. Overall, this study revealed that surface current patterns in the Gulf of Thailand changed from one season to another, provided evidence for changes in spring and neap tide signal (during monsoon events), and the possible existence of anti-cyclonic eddies (driven by monsoon events).
\end{abstract}

Keywords: Harmonic analysis, residual current, tidal ellipse.

ENGINEERING JOURNAL Volume 21 Issue 4

Received 30 September 2016

Accepted 29 December 2016

Published 31 July 2017

Online at http://www.engj.org/

DOI:10.4186/ej.2017.21.4.25 


\section{Introduction}

The Gulf of Thailand is a semi-enclosed, shallow coastal basin situated in the northwestern part of the Sundra Shelf. This area is heavily utilized for tourism activities, artisan and commercial fisheries, natural gas industries, and maritime traffic; all of these activities can result in ocean pollution and/or marine accidents. For example, the oil spill off the coast of Rayong Province, Thailand on July 27, 2013 caused approximately 50,000 liters of crude oil to be released into coastal waters. A strong northeast prevailing wind enhanced dispersal of oil toward Samed Island, a popular tourist attraction on the east coast of Thailand. This incident damaged both coastal environments and economies in all impacted areas.

The movement of an oil slick on the coastal ocean surfaces is a result of surface currents that are caused by tides, wind, and other factors. Hence, it is necessary to understand surface current patterns in the coastal areas to understand and/or predict the impacts of contaminants. In order to understand surface current patterns, numerical modeling and/or field measurements are required. One technology used to measure surface currents is high frequency radar (HF radar) system.

Shore-based HF radar systems can measure and map surface currents to distance approximately 200 kilometers from the shoreline depending on the frequency employed. The small discrepancy in frequency (Doppler shift) between the transmitted signal from an onshore instrument and the backscattered signal from the sea surface is analyzed to obtain the motion of sea surface waters $[1,2,3,4,5]$. One of the advantages of HF radar over other current measurement technologies is the ability to simultaneously measure variability in both time and space [6]. Numerous previous studies have revealed positive advantages of HF radar in coastal sciences, for example, the validation of HF radar [7]; model validation [8, 9, 10, 11, 12]; HF radar and satellite data comparison [13]; data assimilation [14, 15]; and surface current patterns $[16,17,18,6,19]$. In addition, HF radar can be used to predict the arrival time of tsunami waves [20] and to indirectly estimate wind speeds [21].

Since 2011, surface currents derived from HF radar in Thai Waters have been measured by two government agencies, the Thai Meteorological Department (TMD) and the Geo-Informatics and Space Technology Development Agency (GISTDA). In total, 18 stations have been installed along the coast of Thailand in both the Gulf of Thailand and the Andaman Sea. Thus, there are more than 5 years of continuous surface current data in Thailand available from the two agencies. However, research and/or publications related to such measurements/data in Thai Waters are not available.

The objective of this study was to investigate the seasonal surface current patterns derived from HF radar systems in the Gulf of Thailand. Due to the sparsity of space-time data, only the surface current data obtained from GISTDA were used. Hourly total surface currents of one month data for each season were analyzed to describe the circulation patterns in the Gulf of Thailand.

\section{Materials and Methods}

There are three sites, with a total of 12 stations, of HF radar measurement along the coast of Thailand operated by GISTDA, including the Upper Gulf (UGOT), Central Gulf (CGOT) and Lower Gulf (LGOT) of Thailand (Fig. 1; the names and geographical coordinates of each station are shown in Table 1). In this study, the total vector currents (hourly data; $u$ - and $v$-velocity components) derived from the radial currents at each site were retrieved from the GISTDA website for two periods, during the northeast monsoon (January 24, 2015 - February 22, 2015) and the southwest monsoon (May 25, 2015 - June 23, 2015). The maximum number of hourly data points for each season is 720 ; each data point with less than 648 points $(90 \%)$ for the northeast monsoon and 576 points $(80 \%)$ for the southwest monsoon was excluded from the analyses. Mathematically, tides in the ocean can be represented as the supperposition of sinuosoidal waves, each of which have their own amplitude and frequency. Generally, there are approximately 4 major components representing tides in the ocean, which are K1, O1, M2 and S2 (name, symbol, period and frequency of each components are presented in Table 2). Tidal parameters, major axis, minor axis, and ellipse orientation of four major tidal components as mentioned above were extracted from surface current data using tidal harmonic analysis software, UTide [22]. 
These parameters were plotted as a tidal ellipse for each site and season to characterize the major tidal components in the area.

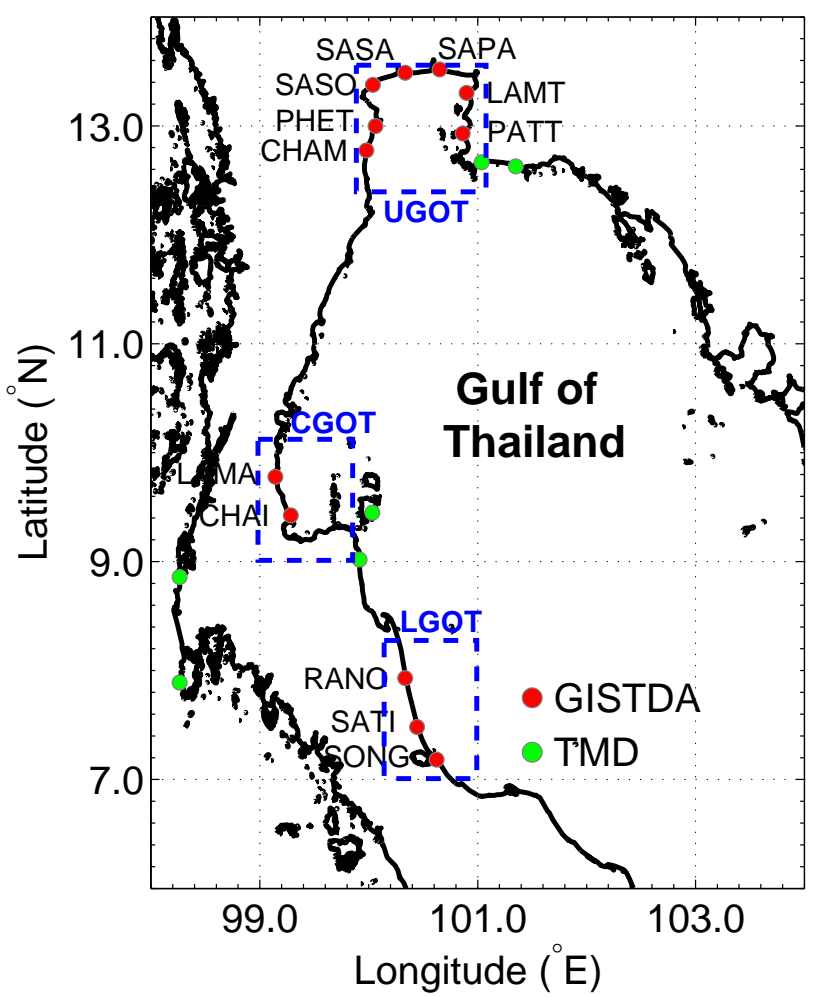

Fig. 1. HF radar stations along the Gulf of Thailand and Andaman Sea. There are total of 12 stations at three sites, UGOT, CGOT, and LGOT (blue boxes) that were used for this study.

Table 1. Geographical coordinate of HF radar station along the coast of the Gulf of Thailand operated by GISTDA.

\begin{tabular}{|l|c|c|c|}
\hline Site & Station & Longitude (Degree E) & Latitude (Degree N) \\
\hline UGOT & PATT & 100.86 & 12.93 \\
& LAMT & 100.90 & 13.30 \\
& SAPA & 100.65 & 13.52 \\
& SASA & 100.34 & 13.49 \\
& PHET & 100.06 & 13.00 \\
& SASO & 100.04 & 13.38 \\
& CHAM & 99.98 & 12.77 \\
\hline CGOT & LAMA & 99.14 & 9.78 \\
& CHAI & 99.28 & 9.43 \\
\hline LGOT & RANO & 100.34 & 7.93 \\
& SATI & 100.44 & 7.48 \\
& SONG & 100.62 & 7.17 \\
\hline
\end{tabular}

To investigate the possibility that wind fields may influence the surface current patterns, a 6-hour reanalysis of wind data (ERA-interim), which was obtained from the European Centre for MediumRange Weather Forecasts (ECMWF) was utilized [23]. Figure 2 demonstrates time series of area averaged of wind velocities at UGOT, CGOT and LGOT during northeast and southwest monsoons. Detail discussions will be mentioned in the next section. 
Table 2. Name, symbol, period and frequency of 4 major tidal components used in this study.

\begin{tabular}{|l|c|l|c|}
\hline Name & Symbol & Period (hour) & Frequency (degree/hour) \\
\hline Luni-solar Declinational diurnal & K1 & 23.93446966 & 15.0410686 \\
Principal Lunar Declinational diurnal & O1 & 25.81934166 & 13.9430356 \\
Principal Lunar semidiurnal & M2 & 12.42060122 & 28.9841042 \\
Principal Solar semidiurnal & S2 & 12.00000000 & 30.0000000 \\
\hline
\end{tabular}
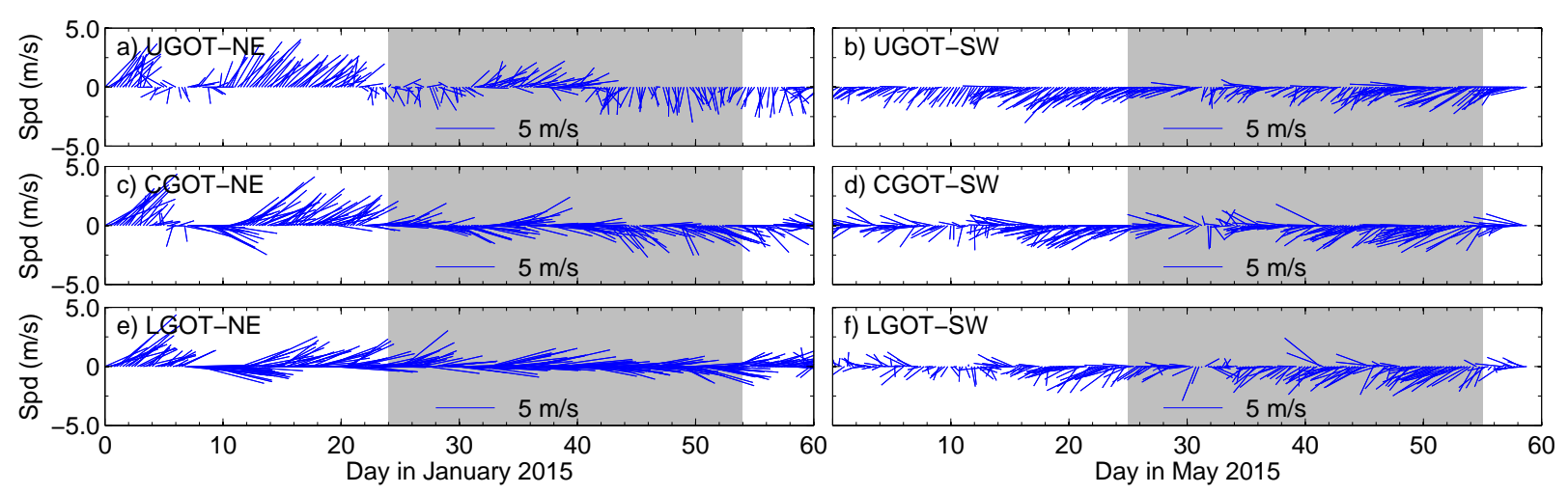

Fig. 2. Area averaged (over $6 \mathrm{hr}$ intervals) time series of wind velocities at UGOT (a and b), CGOT (c and d), and LGOT (e and f). Left and right panels represent northeast and southwest monsoons, respectively. Shaded areas depict time that surface current were averaged.

\section{Results and Discussion}

\subsection{Residual Currents}

The surface current patterns mapped by HF radar at UGOT, CGOT and LGOT are plotted in Fig. 3, Fig. 4 and Fig. 5, respectively. These plots (Fig. 3, Fig. 4 and Fig. 5) are monthly averaged, a data analysis strategy that removes tidal driven currents from the analyses. Hence, the velocity fields in each figure represent the others forces that caused the movement of surface waters, such as winds, waves, density, etc.

The dominant residual current found in the UGOT had a magnitude less than $5.0 \mathrm{~cm} / \mathrm{s}$ in both seasons (Fig. 3). The circulation patterns of both seasons were nearly identical, which had northeastward movements toward the shallow zones in the upper half of the area, while there were eastward and southward flows in the lower half of the UGOT. The clockwise/counter-clockwise circulation during the southwest/northeast monsoon in the UGOT based on 3D hydrodynamics model studies $[24,25]$ was not clearly evident from surface current observations based on HF radar. Furthermore, at the entrance of the UGOT, a clockwise circulation and a southward flow along the west coast were apparently observed in both monsoons.

The area averaged wind velocity obtained from ECMWF [23] for the UGOT during the northeast monsoon (shaded area in Fig. 2(a)) indicated that southerly/southeasterly winds were predominant most of the time, while the expected northeasterly winds were only found for a short period of time (around 10 days). During the southwest monsoon (Fig. 2(b)), winds prevailed mostly from the southwest direction. Consider the wind velocity data in the UGOT, it was found that the averaged wind speed (direction) were $0.83 \mathrm{~m} / \mathrm{s}$ (125.61 degrees) and $2.48 \mathrm{~m} / \mathrm{s}$ (249.26 degrees) for northeast and southwest monsoon, respectively. According to wind-driven circulation, in the Northern Hemisphere, the surface current caused by wind stress tends to deviated to the right hand side of the wind direction [26, 25]. Therefore from the averaged wind direction for both monsoons, they can be used to explain why the residual current patterns in both periods were nearly identical and why they circulated in the clockwise direction (From Fig. 2(a) and Fig. 2(b)), southerly and southwesterly winds were predominant). 


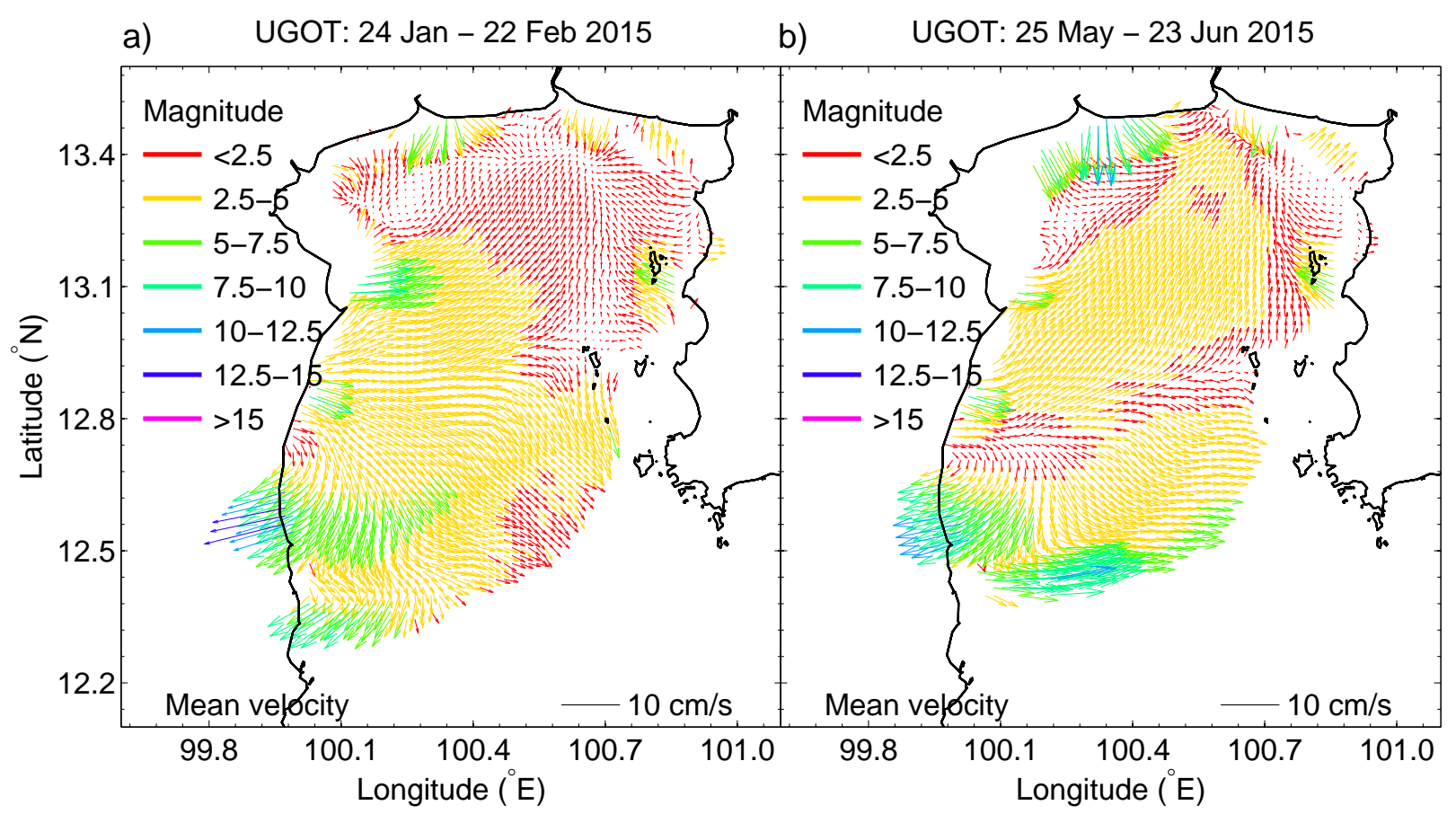

Fig. 3. Averaged surface currents over 720 hourly measurements at UGOT during two different monsoons: a) northeast monsoon (24 January - 22 February 2016); and b) southwest monsoon (25 May 23 June 2016). Scale of the current is shown at the bottom.

Unlike the UGOT, the CGOT was more exposed to external forces such as winds and waves. At the western and southern borders, the CGOT is aligned with the coast; at the northern and eastern borders the CGOT is composed of open waters with some obstructions from the small islands positioned in a north-south direction (see Fig. 1 and Fig. 4). The residual surface current patterns were different from one season to another in the CGOT (Fig. 4). Strong northwestward flows with magnitudes of approximately $15 \mathrm{~cm} / \mathrm{s}$ were observed during the northeast monsoon. On the other hand, $5-10 \mathrm{~cm} / \mathrm{s}$ of northeastward residual currents existed during the southwest monsoon.

The residual current patterns found in this site were also related to the direction of the winds as depicted in Fig. 2(c) and Fig. 2(d), for the northeast and the southwest monsoons, respectively. The averaged wind speed (direction) were $3.28 \mathrm{~m} / \mathrm{s}$ (98.73 degrees) and $3.00 \mathrm{~m} / \mathrm{s}$ (257.85 degrees) for northeast and southwest monsoon, respectively. As mentioned above, northeast to southeast prevailing winds caused the surface flow to move to the right of the wind direction as shown in Fig. 4(a) (wind-driven flow), which would be expected to result in the pile up of water on the west coast. During the southwest monsoon, southwesterly winds caused the surface current to flow in the east to northeast direction (Fig. 4(b)). Considering the magnitude of residual current, it was stronger during the northeast monsoon than during the southwest monsoon (the averaged surface current during northeast and southwest monsoons were 16.6 and $12.1 \mathrm{~cm} / \mathrm{s}$, respectively). This may be explained by the fact that land obstructs the southwesterly winds, which would decrease the wind speed.

Wind velocities in the LGOT presented similar patterns as found in the CGOT (see Fig. 2(e) and Fig. 2(f)). The averaged wind speed (direction) were $4.60 \mathrm{~m} / \mathrm{s}$ (91.49 degrees) and $2.37 \mathrm{~m} / \mathrm{s}(245.62$ degrees) for northeast and southwest monsoon, respectively. Hence, the surface residual current patterns were expected to be the same in the two sites. Geographically, the LGOT has the most exposure to the sea compared to the other two sites. The LGOT is open waters on the eastern side, while a long straight shoreline is situated on the western side. Strong winds and waves during the northeast monsoon may cause strong northwestward longshore transport along the coast (blue shaded arrows in Fig. 5(a)). This strong longshore transport did not exist during the southwest monsoon (Fig. 2(b)); only the northeast flow caused by southwesterly wind were observed. As mentioned above, strong residual 
currents (order of $10-20 \mathrm{~cm} / \mathrm{s}$ ) were observed during the northeast monsoon, while $5-10 \mathrm{~cm} / \mathrm{s}$ residual flows were existent during the southwest monsoon in the CGOT and LGOT. An interesting feature that found during the northeast monsoon was the development of anti-cyclonic eddies or clockwise circulation $[27,28]$ near the northeast corner of the LGOT (see Fig 5(a)). However, these eddies need further study to ascertain if they are noise or if they are real features. For clarity, the question of eddies in the LGOT should be revisited by means of numerical model experiments and/or the analysis of new data sets covering different northeast monsoon periods.

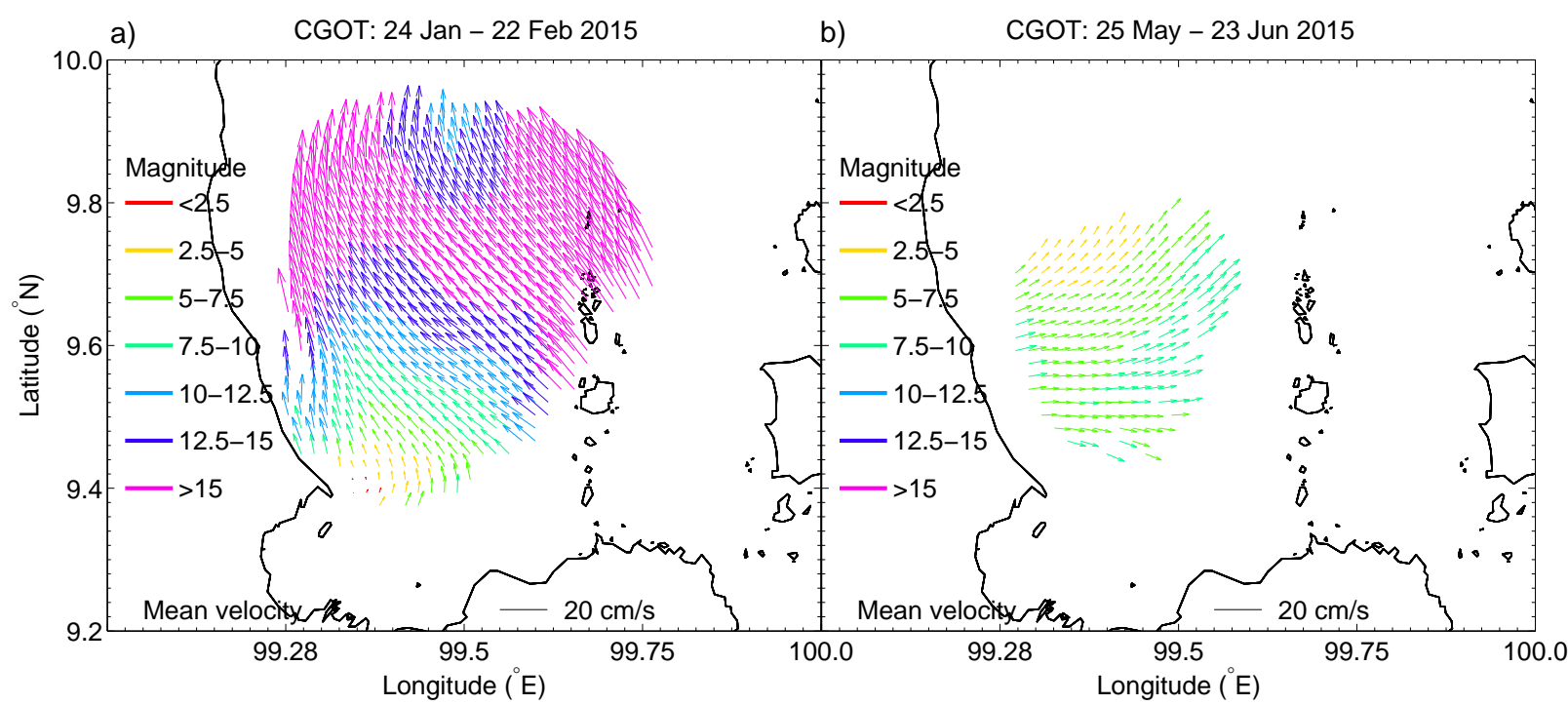

Fig. 4. Averaged surface currents over 720 hourly measurements at CGOT. Details are the same as Fig. 3.

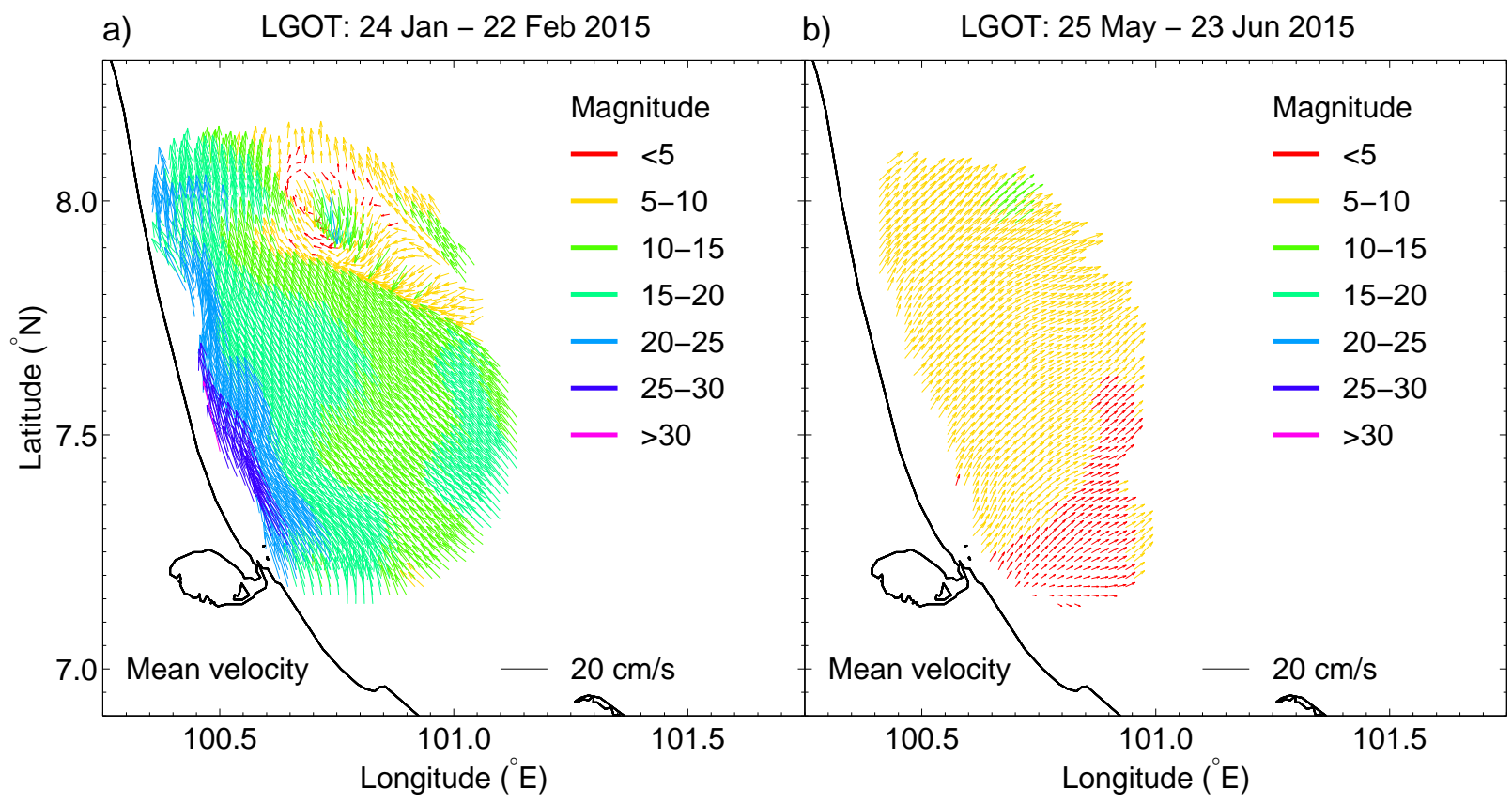

Fig. 5. Averaged surface currents over 720 hourly measurements at LGOT. Details are the same as Fig. 3. 


\subsection{Area Averaged Surface Current}

The analyses described above demonstrated surface currents in the Gulf of Thailand when tidal signals were disregarded (i.e., fluctuations of surface currents due to tides were removed from Fig. 3, Fig. 4 and Fig. 5 in the process of creating monthly averaged data). While monthly averaged (tide signal removed) data have benefits, they also miss salient points related to tides and/or other short-term events. There are two predominant methods to investigate short-time events related to fluctuations of surface currents in time based on HF radar data: 1) applying area averaging to the data; or 2) considering the time series of surface currents for particular points of interest. To include all data points in each of the three study sites examined here, an area averaging of surface currents was selected. Figure 6 shows an area averaging of surface currents at all three sites and for both monsoons. At the UGOT, tide was clearly the major force causing water movement the north-south direction (see Fig. 6(a) and Fig. 6(b)). The time variation in tidal currents in the UGOT coincided with spring and neap tides. Strong and slow surface currents existed during spring and neap tides, respectively. The area averaged current was found to be approximately 5 and $35 \mathrm{~cm} / \mathrm{s}$ during neap and spring tides, respectively. At the CGOT and LGOT, time variations in surface currents showed similar features. However, the magnitude of area averaged current in these 2 sites was in the order of $5-30 \mathrm{~cm} / \mathrm{s}$. During southwest monsoon, tides were the most dominant force controlling the flows in these sites as demonstrated by spring and neap tide features (see Fig. 6(d) and Fig. 6(f)). During high and low tides, northeastward and southeastward flows were present, in contrast, during the northeast monsoon spring and neap tide features disappeared. Therefore, tides were not the major force in these two sites during the northeast monsoon. It was found that most of the time surface currents flowed in a northwest direction, which was consistent with the time averaged surface currents as explained above (see Figure $4 \mathrm{a}$ and $5 \mathrm{a}$ ). Easterly winds, as depicted in Fig. 2(c) and Fig. 2(e), may play significant roles to overrule tidal forcing. This could explain why spring and neap tide features disappeared. However, this statement needs further investigation (e.g., wind-driven currents can be studied by using numerical hydrodynamics models). In addition, during the northeast monsoon, strong wave force and high peak of water level at the CGOT and LGOT causes the existence of the longshore transport in the northward direction. As a result, sediment is transported northward along the shoreline [29].

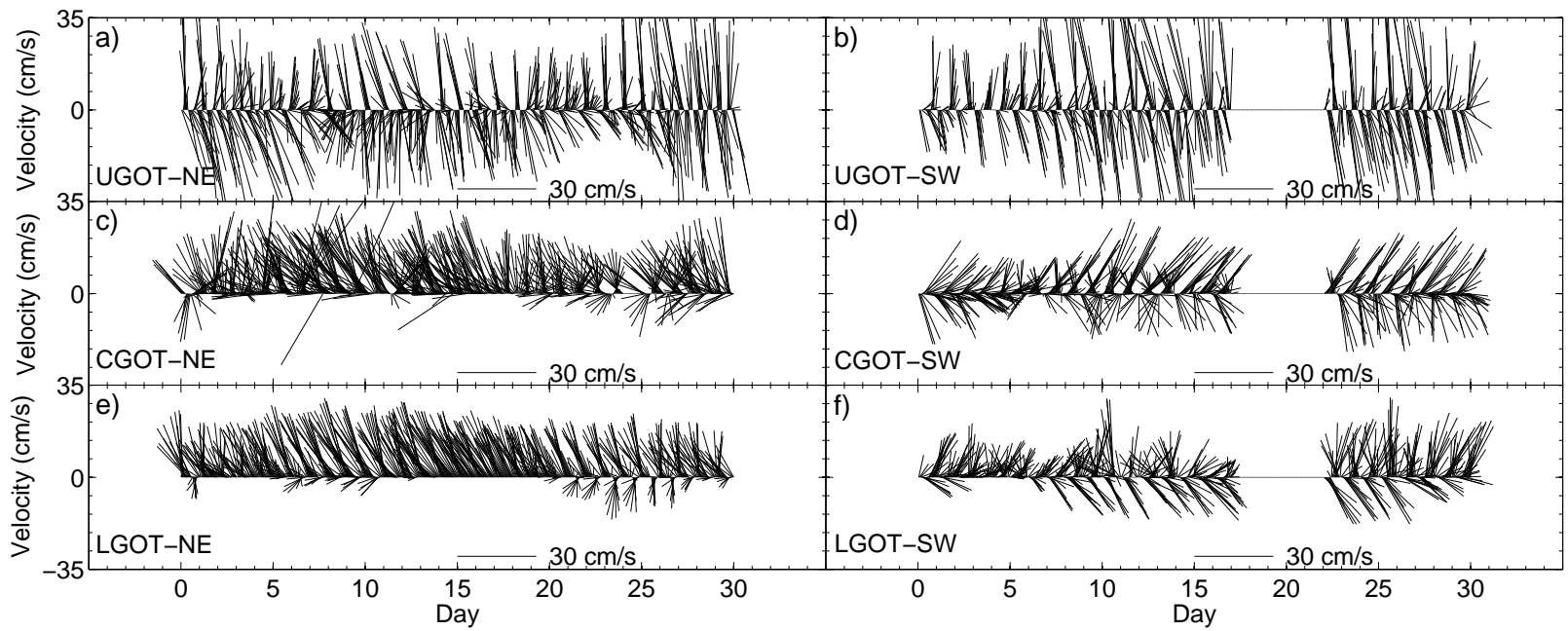

Fig. 6. Spatially averaged surface current time variations at UGOT, CGOT, and LGOT over the 30 day period. Left panel depicts the variations during the northeast monsoon (NE), while the right panel is for the southwest monsoon (SW). 


\subsection{Harmonic Analysis of Surface Currents}

The previous sections explain time and area averaged surface currents in the Gulf of Thailand and show that the features found in the three sites of study area have both similarity and differences depending on location and season. In this section, UTide software [22] was used to extract semi-major and semi-minor axes for K1, O1, M2, and S2 tidal current components. For brevity, only tidal ellipses (semi-major and semi-minor axes) of $\mathrm{K} 1$ and M2 tidal components for these three sites are shown; moreover, because tidal ellipses during northeast and southwest monsoons had small differences in directions, only the results of the northeast monsoon are shown (see Fig. 7, Fig. 8 and Fig. 9). In the figures, the major and minor axes were plotted in blue and red lines, respectively. The major axis depicts the main direction of tidal current (longest axis), while the minor axis (shortest axis) represents the less dominant [22]. The magnitude of major and minor axes will explain how tidal current circulates in 24 hours. If the magnitude of the minor axis is a half of the major axis that lays in the north-south direction, it is expected to see tidal ellipse elongates in the north-south direction and tidal current propagates around the center of tidal ellipse.

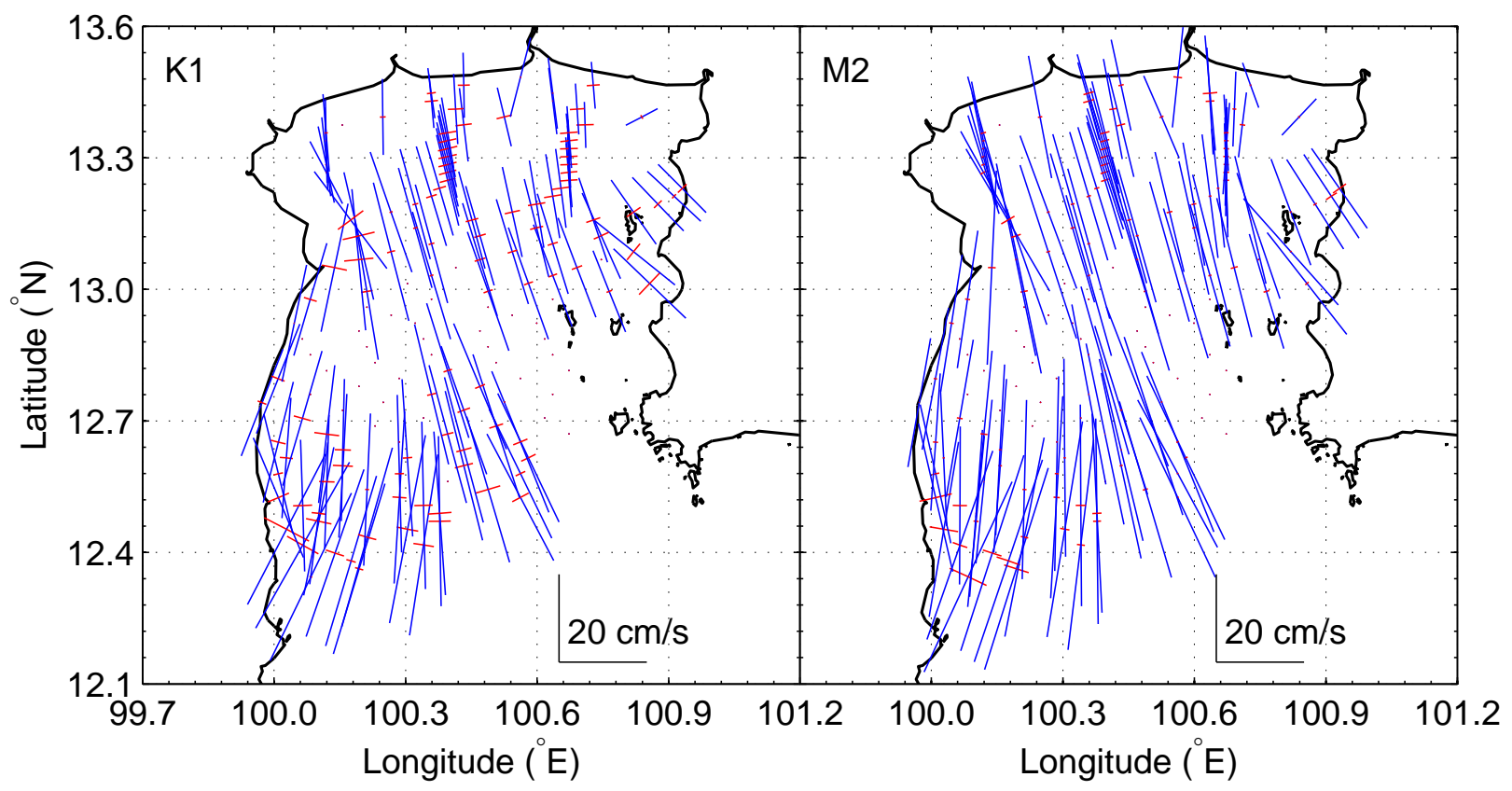

Fig. 7. Tidal ellipse parameters during the northeast monsoon at UGOT. Major axes (blue line) and minor axes (red line) of K1 (left panel) and M2 (right panel).

Most of the data point in the area (both K1 and M2 components) had semi-major axis laid in the north-south direction in the UGOT (Fig. 7). This coincided with the area averaged surface currents shown in Fig. 6(a), which has the flow in a north-south direction. The magnitude of the semi-minor axis was much smaller than the semi-major axis. This further explains how tides significantly propagated in and out the UGOT in the north-south direction. As a result, flood and ebb currents propagated in the north-south direction as mentioned in [25]. More detailed analyses of the UGOT tidal data showed that the orientation angles of all four components (K1, O1, M2 and S2) at each data point in the UGOT mostly had positive signs. Hence, tidal waves circulated in a counter-clockwise direction, consistent with 3D model simulations of this site [24, 25]. Comparing the magnitude of semi-major axis of K1 and M2 tidal components observed in this study it was found that both have nearly the same magnitudes, which are approximately $40 \mathrm{~cm} / \mathrm{s}$. However, the amplitude of K1 and M2 tides obtained from the harmonic analysis of available water level (1 month period) situated in the UGOT found that the K1 tide (a dominant component in the UGOT) was about $10 \mathrm{~cm}$ higher than the M2 tide.

Tidal ellipse of K1 tides differed from M2 tides both in shape and magnitude in the CGOT (see 
Fig. 8). For the K1 component, semi-major and semi-minor axes were less different in magnitude, therefore tidal ellipses were broader than in the case of the UGOT. As for M2 components in the CGOT, the semi-major axis was dominant. However, both tidal current components had semi-major axes mainly laid in the north-south direction. The comparison of magnitude of semi-axis between $\mathrm{K} 1$ and M2 tidal components has shown that magnitude of $\mathrm{K} 1$ component was about 2 times higher than M2 components. This observation coincides with the amplitude of K1 and M2 tides obtained from available water levels in the area, which show that the $\mathrm{K} 1$ tide was a major component in this site. Considering the orientation angles of each component, a positive sign was found in both $\mathrm{K} 1$ and O1 components, therefore these two tidal components propagated in a counter-clockwise direction. For the M2 component, the clockwise circulation was found in the south, while the counter-clockwise circulation was found in the north of the CGOT area.

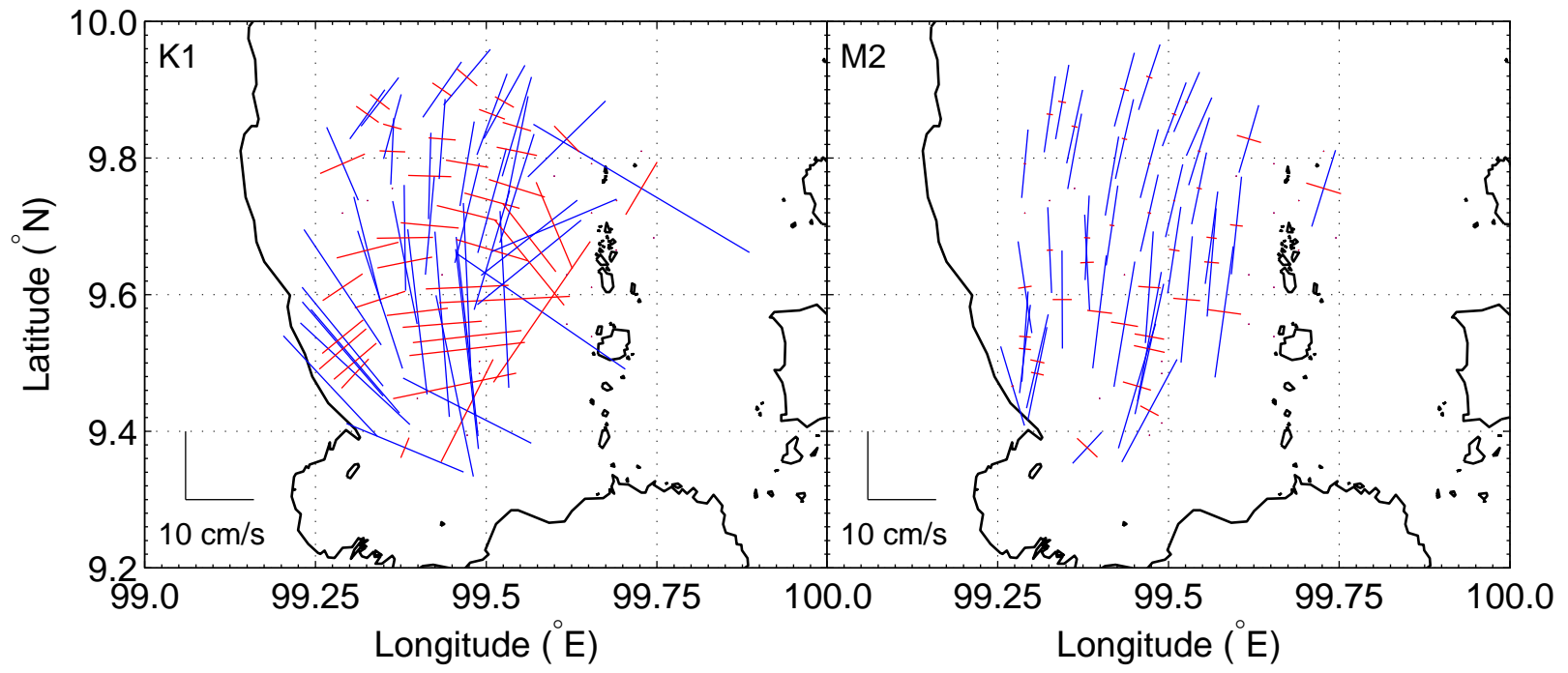

Fig. 8. Tidal ellipse parameters during the northeast monsoon at CGOT. Details as in Fig. 7.

Unlike the other two sites, semi-major axis of M2 component in LGOT was more aligned in the eastwest direction, while the $\mathrm{K} 1$ component still laid in the north-south direction (see Fig. 9). Moreover, for the M2 component the magnitude of semi-minor axis was close to the magnitude of semi-major axis, which was similar to the case of the K1 component of CGOT. In addition, the magnitude of semi-major axis of the $\mathrm{K} 1$ component was about three times larger than the M2 component. The orientation angle of both diurnal (K1 and O1) and semi-diurnal (M2 and S2) components was in the opposite direction. During the northeast and southwest monsoons, diurnal components tended to rotate in the counterclockwise direction, while semi-diurnal components tended to rotate in the clockwise direction.

From the 3D numerical model work for the Eastern Peninsular of Malaysia [30] (Gulf of Thailand is included in the model domain), it was found that K1 tidal component rotated in the counter-clockwise direction in all sites (UGOT, CGOT and LGOT), while M2 tidal component rotated in the clockwise direction. These findings are in agreement with the results found in this study.

\section{Conclusions}

Sea surface current data is crucially important for coastal managers and other agencies involved in marine pollution, marine conflicts, and maritime accidents. Spatial and temporal variations of sea surface currents are also vital in providing information that can predict the future. One detection system that can deal with variations in sea surface currents is HF radar. Recently, in the Gulf of Thailand, HF radar system sites were situated in the Upper Gulf, the Central Gulf and the Lower Gulf. All three sites are operated and maintained by GISTDA. Since there is sparse research on surface current patterns in terms of observation measurements in the Gulf, this paper provided details for monsoon events in 2015. 


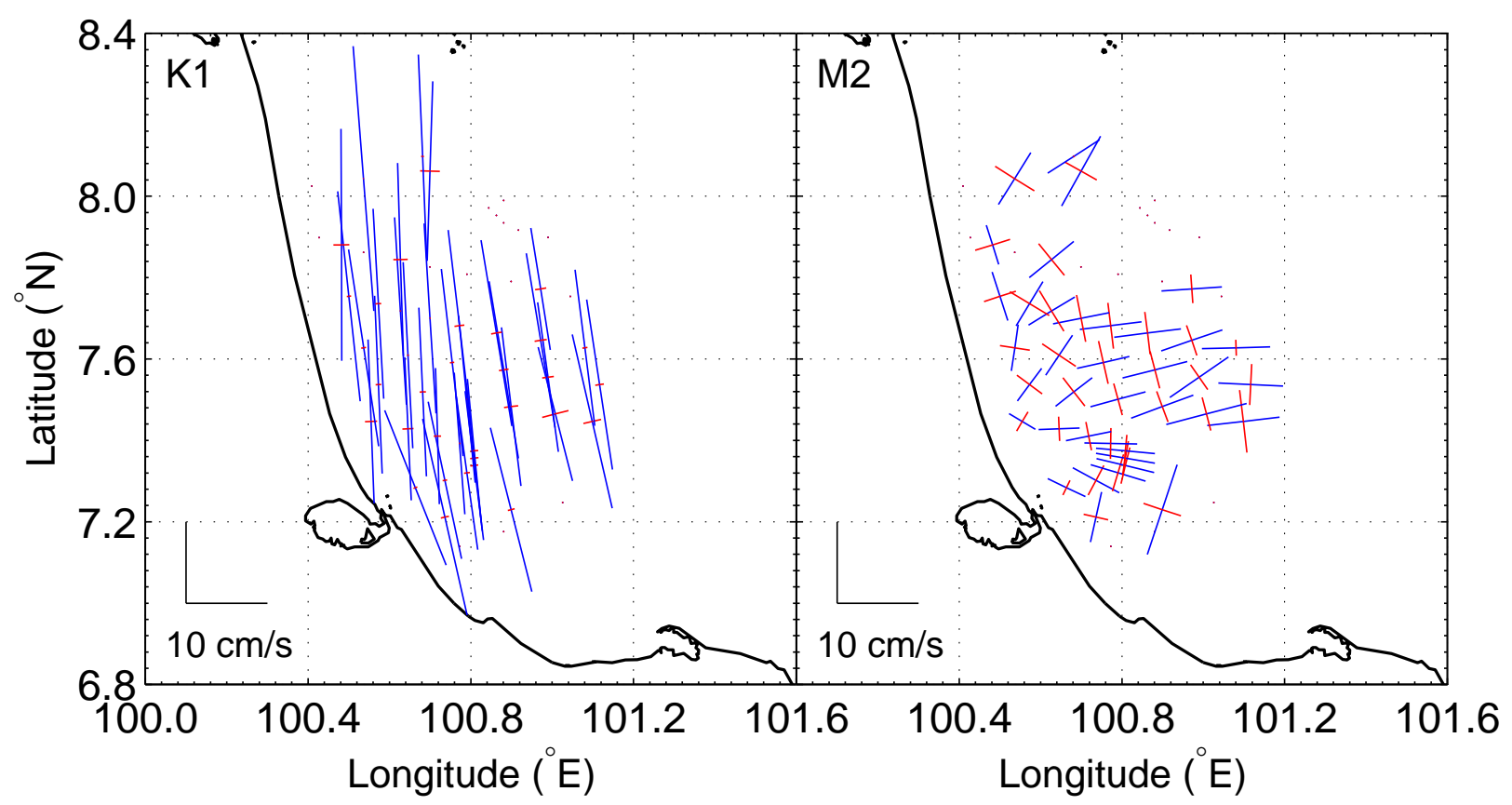

Fig. 9. Tidal ellipse parameters during the northeast monsoon at LGOT. Details as in Fig. 7.

Analysis of 1 month total vector currents for the northeast monsoon and southwest monsoon revealed that surface current pattern in the Gulf of Thailand changed from one season to another. In the UGOT, time averaged surface currents (residual) and area averaged surface currents showed no significant difference between the two seasons. This may be explained by the influence of southerly/southwesterly winds at this site. The north-south current flow direction was significantly controlled by tidal forcing. At CGOT and LGOT, southwesterly winds force the residual surface current to move in the northeast direction. During the northeast monsoon, the easterly winds generated northwestward current flow along the coast on the western side of the UGOT. An interesting feature became evident when area averaging of surface current of CGOT and LGOT was applied during the northeast monsoon; area averaging data showed the disappearance of spring and neap tide signals that are supposed to exist in both sites. Instead of having spring and neap tide signals, results shown here showed strong northwestward flow for almost the entire month. Another interesting feature was the existence of anti-cyclonic eddies located at the top right (i.e., northeast) corner of the LGOT during the southwest monsoon, which may or may not be real features. These last two features require further investigation by means of numerical modeling or the analysis of other sets of data.

Tidal ellipse analysis using UTide software showed that the rotation of each tidal component differed from one area to another area. In the UGOT, a counter-clockwise of all tidal components was dominant for both seasons. At CGOT and LGOT counter-clockwise circulation was dominant for diurnal tidal components (K1 and O1) and vice versa for semi-diurnal tidal components (M2 and S2). Furthermore, at CGOT tidal ellipse for diurnal components was wider than semi-diurnal components, which contrary to the tides in LGOT. The alignment of the semi-major axis of M2 component at LGOT is in the east-west direction, which was clearly different from others site.

This study revealed seasonal variations in surface current patterns exist in the Gulf of Thailand through the analysis of currents obtained from HF radar. There still unclear messages that required further study. Analysis of longer observation data or new data set or numerical model study in each site will be taken into consideration in the future studies. 


\section{Acknowledgements}

This research was partially supported by Grants for Development of New Faculty Staff, Ratchadaphiseksomphot Endowment Fund, Chulalongkorn University. The author very much appreciates Dr. Gerald G. Plumley for his help during manuscript preparation. Special thanks to the Geo-Informatics and Space Technology Development Agency (Public Organization) for total surface current data. The author also thanks the reviewers for the comments to improve the manuscript.

\section{References}

[1] R. H. Stewart and J. W. Joy, "High frequency radio measurements of ocean currents," in Engineering in the Ocean Environment, Ocean 73 - IEEE International Conference on, September 1973, pp. 64-67.

[2] - , "HF radio measurements of surface currents," Deep Sea Research and Oceanographic Abstracts, vol. 21, no. 12, pp. 1039-1049, 1974. [Online]. Available: http://www.sciencedirect.com/science/article/pii/0011747174900667

[3] D. E. Barrick, M. W. Evans, and B. L. Weber, "Ocean surface currents mapped by radar," Science, vol. 198, no. 4313, pp. 138-144, 1977.

[4] J. D. Paduan and L. Washburn, "High-Frequency Radar Observations of Ocean surface Currents," Annual Review of Marine Science, vol. 5, no. 1, pp. 115-136, 2013. [Online]. Available: http://dx.doi.org/10.1146/annurev-marine-121211-172315

[5] A. Joseph, "Chapter 4 - Remote Mapping of Sea Surface Currents Using HF Doppler Radar Networks," in Measuring Ocean Currents, A. Joseph, Ed. Boston: Elsevier, 2014, pp. 109-137. [Online]. Available: http://www.sciencedirect.com/science/article/pii/B9780124159907000041

[6] R. Tokeshi, K. Ichikawa, S. Fujii, K. Sato, and S. Kojima, "Estimating the geostrophic velocity obtained by hf radar observations in the upstream area of the kuroshio," Journal of Oceanography, vol. 63, no. 4, pp. 711-720, 2007. [Online]. Available: http://dx.doi.org/10.1007/s10872-0070062-1

[7] P. Lorente, S. Piedracoba, and E. A. Fanjul, "Validation of high-frequency radar ocean surface current observations in the nw of the Iberian Peninsula," Continental Shelf Research, vol. 92, pp. $1-15,2015$.

[8] D. Prandle and D. Ryder, "Comparison of observed (HF radar) and modelled nearshore velocities," Continental Shelf Research, vol. 9, no. 11, pp. 941-963, 1989. [Online]. Available: http://www.sciencedirect.com/science/article/pii/0278434389900010

[9] D. Prandle, "A new view of near-shore dynamics based on observations from HF Radar," Progress in Oceanography, vol. 27, no. 3, pp. 403-438, 1991. [Online]. Available: http://www.sciencedirect.com/science/article/pii/007966119190030P

[10] A. M. Davies, P. Hall, M. J. Howarth, P. Knight, and R. Player, "A detailed comparison of measured and modeled wind-driven currents in the North Channel of the Irish Sea," Journal of Geophysical Research: Oceans, vol. 106, no. C9, pp. 19683-19713, 2001. [Online]. Available: http://dx.doi.org/10.1029/2001JC900005

[11] J.-C. Mau, D.-P. Wang, D. S. Ullman, and D. L. Codiga, "Comparison of observed (hf radar, adcp) and model barotropic tidal currents in the new york bight and block island sound," Estuarine, Coastal and Shelf Science, vol. 72, no. 1-2, pp. 129-137, 2007. [Online]. Available: http://www.sciencedirect.com/science/article/pii/S0272771406004872

[12] F. O’Donncha, M. Hartnett, S. Nash, L. Ren, and E. Ragnoli, "Characterizing observed circulation patterns within a bay using HF radar and numerical model simulations," Journal of Marine Systems, vol. 142, pp. 96-110, 2015. [Online]. Available: http://www.sciencedirect.com/science/article/pii/S0924796314002346 
[13] A. Pascual, A. Lana, C. Troupin, S. Ruiz, Y. Faugère, R. Escudier, and J. Tintoré, "Assessing SARAL/AltiKa Data in the Coastal Zone: Comparisons with HF Radar Observations," Marine Geodesy, vol. 38, no. sup1, pp. 260-276, 2015. [Online]. Available: http://dx.doi.org/10.1080/01490419.2015.1019656

[14] E. V. Stanev, J. Schulz-Stellenfleth, J. Staneva, S. Grayek, J. Seemann, and W. Petersen, "Coastal observing and forecasting system for the german bight - estimates of hydrophysical states," Ocean Science, vol. 7, no. 5, pp. 569-583, 2011. [Online]. Available: http://www.oceansci.net/7/569/2011/

[15] G. Gopalakrishnan and A. F. Blumberg, "Assimilation of HF radar-derived surface currents on tidal-timescales," Journal of Operational Oceanography, vol. 5, no. 1, pp. 75-87, 2012. [Online]. Available: http://dx.doi.org/10.1080/1755876X.2012.11020133

[16] D. Prandle, "The Fine-Structure of Nearshore Tidal and Residual Circulations Revealed by H.F. Radar Surface Current Measurements," Journal of Physical Oceanography, vol. 17, no. 2, pp. 231-245, 1987. [Online]. Available: http://dx.doi.org/10.1175/15200485(1987)017<0231:TFSONT > 2.0.CO;2

[17] G. Marmorino, L. Shay, B. Haus, R. Handler, H. Graber, and M. Horne, "An EOF analysis of HF Doppler radar current measurements of the Chesapeake Bay buoyant outflow," Continental Shelf Research, vol. 19, no. 2, pp. 271-288, 1999. [Online]. Available: http://www.sciencedirect.com/science/article/pii/S0278434398000788

[18] T. M. Cook and L. K. Shay, "Surface M2 tidal currents along the North Carolina shelf observed with a high-frequency radar," Journal of Geophysical Research: Oceans, vol. 107, no. C12, pp. 15-1-15-12, 2002, 3222. [Online]. Available: http://dx.doi.org/10.1029/2002JC001320

[19] M. K. Gough, N. Garfield, and E. McPhee-Shaw, "An analysis of HF radar measured surface currents to determine tidal, wind-forced, and seasonal circulation in the Gulf of the Farallones, California, United States," Journal of Geophysical Research: Oceans, vol. 115, no. C4, 2010, c04019. [Online]. Available: http://dx.doi.org/10.1029/2009JC005644

[20] B. Lipa, J. Isaacson, B. Nyden, and D. Barrick, "Tsunami Arrival Detection with High Frequency (hf) Radar," Remote Sensing, vol. 4, no. 5, pp. 1448 - 1461, 2012. [Online]. Available: http://www.mdpi.com/2072-4292/4/5/1448

[21] W. Shen, K.-W. Gurgel, G. Voulgaris, T. Schlick, and D. Stammer, "Wind-speed inversion from HF radar first-order backscatter signal,” Ocean Dynamics, vol. 62, no. 1, pp. 105-121, 2012. [Online]. Available: http://dx.doi.org/10.1007/s10236-011-0465-9

[22] D. L. Codiga, "Unified tidal analysis and prediction using the Utide Matlab functions," Graduate School of Oceanography, University of Rhode Island, Narragansett, Rhode Island, USA, Tech. Rep., 2011.

[23] D. P. Dee, S. M. Uppala, A. J. Simmons, P. Berrisford, P. Poli, S. Kobayashi, U. Andrae, M. A. Balmaseda, G. Balsamo, P. Bauer, P. Bechtold, A. C. M. Beljaars, L. van de Berg, J. Bidlot, N. Bormann, C. Delsol, R. Dragani, M. Fuentes, A. J. Geer, L. Haimberger, S. B. Healy, H. Hersbach, E. V. Hólm, L. Isaksen, P. Kållberg, M. Köhler, M. Matricardi, A. P. McNally, B. M. Monge-Sanz, J.-J. Morcrette, B.-K. Park, C. Peubey, P. de Rosnay, C. Tavolato, J.-N. Thépaut, and F. Vitart, "The ERA-Interim reanalysis: configuration and performance of the data assimilation system," Quarterly Journal of the Royal Meteorological Society, vol. 137, no. 656, pp. 553-597, 2011. [Online]. Available: http://dx.doi.org/10.1002/qj.828

[24] A. Buranapratheprat, K. O. Niemann, T. Yanagi, S. Matsumura, and P. Sojisuporn, "Circulation in the Upper Gulf of Thailand investigated using a three-dimensional hydrodynamics model," $\mathbf{B u}$ rapha Science Journal, vol. 14, no. 1, pp. 99-113, 2009.

[25] S. Saramul and T. Ezer, "On the dynamics of low latitude, wide and shallow coastal system: numerical simulations of the Upper Gulf of Thailand," Ocean Dynamics, vol. 64, no. 4, pp. 557-571, 2014. [Online]. Available: http://dx.doi.org/10.1007/s10236-014-0703-z 
[26] J. F. Price, R. A. Weller, and R. R. Schuldlich, "Wind-driven ocean currents and Ekman transport," Science, vol. 238, no. 4833, pp. 1534-1538, 1987. [Online]. Available: http://science.sciencemag.org/content/238/4833/1534

[27] R. M. Kudela, A. R. Horner-Devine, N. S. Banas, B. M. Hickey, T. D. Peterson, R. M. McCabe, E. J. Lessard, E. Frame, K. W. Bruland, D. A. Jay, J. O. Peterson, W. T. Peterson, P. M. Kosro, S. L. Palacios, M. C. Lohan, and E. P. Dever, "Multiple trophic levels fueled by recirculation in the columbia river plume," Geophysical Research Letters, vol. 37, no. 18, pp. n/a-n/a, 2010, 118607. [Online]. Available: http://dx.doi.org/10.1029/2010GL044342

[28] P. Yu, A. L. Kurapov, G. D. Egbert, J. S. Allen, and P. M. Kosro, "Variational assimilation of HF radar surface currents in a coastal ocean model off oregon," Ocean Modelling, vol. 49-50, pp. 86 - 104, 2012. [Online]. Available: http://www.sciencedirect.com/science/article/pii/S1463500312000364

[29] S. Pornpinatepong, H. Tanaka, and T. Chittrakarn, "Coastal dynamics and shore erosion in Songkhla," in Proceedings of the Fourth PSU Engineering Conference, Hat Yai, Thailand, 1996, pp. $135-140$.

[30] F. T. Tangang, C. Xia, F. Qiao, L. Juneng, and F. Shan, "Seasonal circulations in the Malay Peninsula Eastern continental shelf from a wave-tide-circulation coupled model," Ocean Dynamics, vol. 61, no. 9, pp. 1317-1328, 2011. [Online]. Available: http://dx.doi.org/10.1007/s10236-011$0432-5$ 